\title{
Relationship between different particle size fractions and all-cause and cause-specific emergency ambulance dispatches
}

\author{
Xiaojie Wang ${ }^{1 \dagger}$, Junzhang Tian ${ }^{1 \dagger}$, Ziyi Li ${ }^{1}$, Jun Lai ${ }^{2}$, Xin Huang ${ }^{1}$, Yongcong He ${ }^{2}$, Zebing Ye ${ }^{2^{*}}$ and Guowei $\mathrm{Li}^{1,3^{*}}$ (D)
}

\begin{abstract}
Background: Evidence on the relationship between different particle size fractions and emergency ambulance dispatches (EAD) remains limited and sparse.

Methods: We collected daily data of EAD, ambient air pollution and meteorological data from 2014 to 2018 in Guangzhou, China. We used a generalized additive model with covariate adjustments to estimate the associations between different particle size fractions and EAD related to all-cause, cardiovascular diseases, and respiratory diseases. Several subgroup and sensitivity analyses were also performed.

Results: Significant associations were observed between $\mathrm{PM}_{2.5}, \mathrm{PM}_{2.5-10}, \mathrm{PM}_{10}$ and EADs. A $10 \mu \mathrm{g} / \mathrm{m}^{3}$ increase of $\mathrm{PM}_{2.5}, \mathrm{PM}_{2.5-10}$, and $\mathrm{PM}_{10}$ was associated with an increase of $0.98 \%$ (95\% Cl: 0.67, 1.28\%), 2.06\% (95\% Cl: 1.44, 2.68\%), and $0.75 \%$ (95\% Cl: $0.53,0.96 \%)$ in all-cause EAD, with an increase of $0.69 \%$ (95\% Cl: $0.00,1.39 \%), 2.04 \%$ (95\% Cl: 0.64 , $3.45 \%)$, and $0.60 \%$ (95\%Cl: $0.11,1.10 \%)$ in cardiovascular-related EAD, and an increase of 1.14\% (95\% Cl: $0.25,2.04 \%)$, 2.52\% (95\% Cl: $0.72,4.35 \%)$, and $0.89 \%$ (95\%Cl: $0.25,1.52 \%)$ in respiratory-related EAD at lag03, respectively. The results were robust in subgroup and sensitivity analyses.
\end{abstract}

Conclusions: This study revealed that $\mathrm{PM}_{2.5}, \mathrm{PM}_{2.5-10}$ and $\mathrm{PM}_{10}$ were significantly related with risks of all-cause and cause-specific EAD. More evidence of high quality may be needed to further support our results in this ecological study.

Keywords: Particulate matter, Particle size, Emergency ambulance dispatches

\section{Introduction}

Exposures to ambient particulate matter (PM) have been consistently linked with human health [1-3]. The World Health Organization (WHO) reported that ambient PM was a major environmental risk to human health, and it was one of the leading causes of death and disability worldwide, especially in low- and middle-income countries [4].

\footnotetext{
* Correspondence: jzhzang@163.com; lig28@mcmaster.ca

${ }^{+}$Xiaojie Wang and Junzhang Tian contributed equally to this work.

2Department of Cardiology, Guangdong Second Provincial General Hospital,

Guangzhou, China

${ }^{1}$ Center for Clinical Epidemiology and Methodology (CCEM), Guangdong

Second Provincial General Hospital, Guangzhou, China

Full list of author information is available at the end of the article
}

Most of the previous studies have investigated the health effects of PM pollution with an aerodynamic diameter less than $10 \mu \mathrm{m}\left(\mathrm{PM}_{10}\right)$ and $2.5 \mu \mathrm{m}\left(\mathrm{PM}_{2.5}\right)[5,6]$, and evidence of adverse health effects of these has played an important role in the formulation of air quality standards [7]. Moreover, coarse particulate $\left(\mathrm{PM}_{2.5-10}\right)$, defined as $\mathrm{PM}$ between 2.5 and $10 \mu \mathrm{m}$ in aerodynamic diameter, has been also found to have effects on adverse outcomes $[8,9]$. However, even though high levels of particulate air pollutants are often observed, evidence of relationship between PM pollution and human health remains sparse in China, making region-specific results difficult to interpret and compare with those from developed countries. 
The majority of prior studies found that PM pollution was associated with mortality, morbidity and hospitalization $[10,11]$. While only a limited number of studies focused on the associations between PM pollution and emergency ambulance dispatches (EAD) [12, 13], their findings remained inconsistent. For instance, a study used time-series design in Australia reported that $\mathrm{PM}_{2.5}$ and $\mathrm{PM}_{2.5-10}$ were significantly and positively associated with EAD [13]. However, another study in the U.S. using a case-crossover design found no association between short-term $\mathrm{PM}_{2.5}$ exposure and EAD [14].

Recent epidemiological studies have examined the acute effects of PM pollution on morbidity by using hospital admissions and emergency department visits as indicators. Nevertheless, databases of morbidity information across multiple hospitals for epidemiological studies has not been fully established in China. In recent years, some studies $[13,15]$ have used EAD as a morbidity indicator to examine the health effects of PM pollution. It is also reported that EAD may be a more appropriate variable to capture the acute effects of air pollution compared with morbidity and mortality $[16,17]$. However, the evidence remains sparse and limited about the relationship between different particle size fractions and all-cause and cause-specific EAD in China. Therefore, our purpose was to quantitatively assess the short-term associations between different particle sizes of air pollution and EAD in China. A better understanding of the association between PM pollution and EAD may help inform policy-making of air pollution control and provide better knowledge of the etiology of the related diseases.

\section{Methods}

\section{Setting}

Guangzhou, located in Southern China, belongs to a subtropical humid-monsoon climate. Its annual mean temperature is $22^{\circ} \mathrm{C}$ and the average rainfall is 1500 $2000 \mathrm{~mm}$. It is the third-largest city in China with 12.7 million people in 2010 [18]. In the last decades, alongside the fast development, serious air pollution has been witnessed among Chinese cities, including Guangzhou [19]. The residents living in urban districts of Guangzhou were selected for this study for two reasons. First, there were nearby air monitoring stations around these districts, and thus, less exposure measurement errors were induced. Second, urban districts have health outcome data of higher quality [20].

\section{Health data}

We obtained the daily counts of EAD due to all-cause, cardiovascular diseases, and respiratory diseases from May 2014 to December 2018 from the Guangzhou Emergency Center. This center serves about seven million people living in urban areas of Guangzhou and is the primary emergency dispatch agency. This center coordinates efforts for approximately 200 ambulances and ensures that emergency responses occur within $30 \mathrm{~min}$ after receiving an emergency call, irrespective of the time of day [21]. Ethical approval was not required in this study because no patient privacy was involved and all the data were publicly accessible.

After each emergency call, a standardized data entry form was completed by trained medical personnel. The form included the demographic information, main symptoms, and clinical diagnosis of patients. Diseases were diagnosed by physicians based on the patients' symptoms, inquiries, and medical examination in standardized procedures where strict quality assurance and quality control were applied. EAD due to traumatic accidents, suicide events, pregnancy and delivery-related events were excluded for analyses in our study. The determination of cardiovascular and respiratory events diagnosis was made by field emergency physicians based on patients' symptoms and signs. Therefore, it was expected the misclassification rate to be relatively small [22]. Daily counts of EAD were tabulated to construct the time series.

\section{Air pollution and meteorological data}

Daily concentrations of air pollution were obtained from 11 air monitoring stations in Guangzhou during the period from May 2014 to December 2018 (Their distribution is shown in Fig. 1). We measured the daily mean concentrations of air pollutants based on the data from 24-h monitoring, in which the pollutants included $\mathrm{PM}_{10}$, $\mathrm{PM}_{2.5}$, nitrogen dioxide $\left(\mathrm{NO}_{2}\right)$, ozone $\left(\mathrm{O}_{3}\right)$ and sulfur dioxide $\left(\mathrm{SO}_{2}\right)$. We estimated $\mathrm{PM}_{2.5-10}$ concentrations by subtracting $\mathrm{PM}_{2.5}$ from $\mathrm{PM}_{10}$, because $\mathrm{PM}_{10}$ was consisted of $\mathrm{PM}_{2.5}$ and $\mathrm{PM}_{2.5-10}$. Daily mean concentrations of each air pollutant across the stations were used to reflect the general population's daily exposure. Approximately $1 \%$ of observation days had missing data for the particle sizes. We did not perform imputations for missing data in our analyses due to the small percentage of missing data. Air pollution measurement details have been previously described [23].

Daily meteorological data (mean temperature and relative humidity) were obtained from the National Weather Data Sharing System (http://data.cma.cn/).

\section{Statistical analysis}

The EAD data, daily air pollution concentrations and meteorological data were linked by date. We assessed the acute associations between PM pollution and daily counts of EAD due to all-cause, cardiovascular diseases, and respiratory diseases using generalized additive models (GAM). To adjust for the over-dispersion in daily EAD counts, a quasi-Poisson link function was 


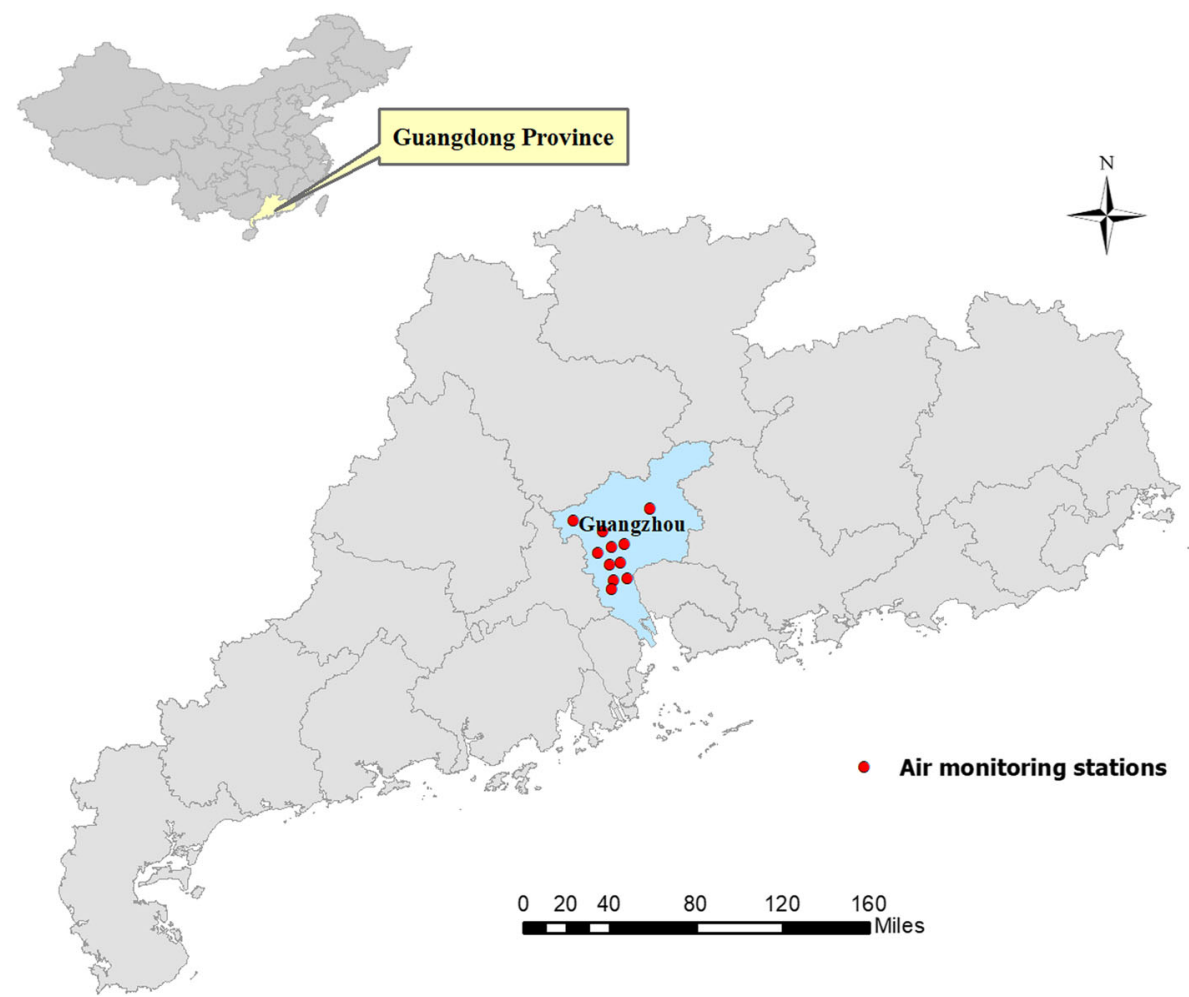

Fig. 1 The geographic distribution of the air monitoring stations in Guangzhou, China

applied. This analysis strategy has been widely used previously $[24,25]$. Day of the week (DOW) and public holidays $(\mathrm{PH})$ were controlled for as categorical variables. Smoothing spline functions with different degrees of freedom were used to control for all the nonlinear timedependent variables including temporal trends and meteorological factors. Similar to previous studies, we selected our model specification a priori for the degrees of freedom ( $\mathrm{df}$ ) for long-term and seasonal trends and other meteorological variables [26]. Specifically, we applied $8 \mathrm{df}$ per year for temporal trends, $6 \mathrm{df}$ for temperatures of the current day and the previous three days moving averages (Temp03), and $3 \mathrm{df}$ for current day's relative humidity [27].

We first generated a base model without PM pollutants. The base model was written as below:

$$
\begin{aligned}
\log [\mathrm{E}(\mathrm{Yt})]= & \alpha+\mathrm{s}(\mathrm{t}, d f=6 / \text { year }+\mathrm{s}(\text { Temp03, } d f \\
= & 6+\mathrm{s}(\text { Humidity }, d f=3)+\beta_{1} * \mathrm{DOW} \\
& +\beta_{2} * \mathrm{PH}
\end{aligned}
$$

where $\mathrm{E}(\mathrm{Yt})$ was the expected $\mathrm{EAD}$ count on day $\mathrm{t}$, $\alpha$ was the model intercept, $s()$ indicated the smoother, $t$ represented the time in order to adjust for long-term and seasonal trends, and $\beta$ was the regression coefficient.

We then included the concentrations of the three size fractions in the regression models separately to examine their associations. Due to the high correlation between the particulate pollutants, we fitted three separate regression models.

To examine the lagged effects of air pollution, models with different lag structures were constructed beginning with the same day (lag0) up to five days lag before (lag5) and with multi-day lags [moving average of current day and previous 1,3 , and 5 days (lag01, lag03, and lag05)]. A maximum of five days was considered because there was little evidence of associations beyond five days in China [28]. We also considered multi-lag days, and the effects at each lag day were finally reported for each size fraction [29].

We conducted stratified analyses to investigate the possible effect modification of the PM pollution-EAD associations by sex (males vs. females), age strata $(<65$ years vs. $\geq 65$ ), and season (cold vs. warm). Warm season was defined as April to September, and cold season was October to March. We tested whether the subgroup differences between effect estimates of the strata were significant by calculating the $95 \%$ confidence interval (CI) as shown below:

$$
\left(Q_{1}-Q_{2}\right) \pm 1.96 \sqrt{\left(\mathrm{SE}_{1}\right)^{2}+\left(\mathrm{SE}_{2}\right)^{2}}
$$

where $\mathrm{Q}_{1}$ and $\mathrm{Q}_{2}$ represented the estimates for the two 
categories (e.g., males and females), and $\mathrm{SE}_{1}$ and $\mathrm{SE}_{2}$ are their corresponding standard errors [30].

To support the robustness of our results, we conducted a series of sensitivity studies. The main findings obtained from the current study were assessed by varying the degrees of freedom in the smooth functions for temporal trends and further by adjusting for gaseous air pollutants $\left(\mathrm{NO}_{2}, \mathrm{O}_{3}\right.$, and $\left.\mathrm{SO}_{2}\right)$. We conducted another sensitivity analysis by controlling longer lag days' temperature and relative humidity (up to 21 days), because previous studies had found that the temperature may have a longer lag of health effect $[19,31]$.

We conducted all the analyses using the "mgcv" package in R (version 3.6.0; R Development Core Team, Vienna, Austria). The effect estimates were reported as excess risk (ER) in daily EAD associated with per $10 \mu \mathrm{m} /$ $\mathrm{m}^{3}$ increase in each PM pollutant, where ER was defined as [relative risk (RR)-1] $100 \%$. Statistical significance was defined as $p<0.05$.

\section{Results}

A total of 586,197 EAD were recorded during the study period, 56,827 of which was for cardiovascular diseases and 38,829 for respiratory diseases. Table 1 summarizes the distribution of daily EAD counts, air pollution, and meteorological variables. On average, there were $391 \mathrm{EAD}$ per day due to all-cause diseases, 38 EAD due to cardiovascular diseases, and $26 \mathrm{EAD}$ due to respiratory diseases. In brief, the daily concentrations of $\mathrm{PM}_{2.5}, \mathrm{PM}_{2.5-10}$, $\mathrm{PM}_{10}, \mathrm{NO}_{2}, \mathrm{O}_{3}$, and $\mathrm{SO}_{2}$ were 36.0, 20.5, 56.5, 44.1, 45.2, and $15.9 \mu \mathrm{g} / \mathrm{m}^{3}$ during $2014-2018$, respectively. The daily mean temperature was $22.2^{\circ} \mathrm{C}$ and relative humidity was $79.6 \%$.

The spearman's correlation coefficients between the air pollutants are shown in Table S1. Generally, $\mathrm{PM}_{2.5}$ was strongly correlated with $\mathrm{PM}_{2.5-10}$ and $\mathrm{PM}_{10}(\mathrm{r}=0.71$ with $\mathrm{PM}_{2.5-10}, \mathrm{r}=0.97$ with $\left.\mathrm{PM}_{10}\right)$. The correlations of particulate matter with $\mathrm{O}_{3}$ and $\mathrm{SO}_{2}$ were relatively low with an $\mathrm{r}$ ranging from 0.09 to 0.33 , while the correlations of $\mathrm{NO}_{2}$ with particulate matter were high ( $\mathrm{r}$ ranging from 0.69 to 0.78 ).

Figure 2 presents the association between PM pollution with different size fractions and EAD over different lag days in the single-pollutant regression models. In general, we found the largest effects at lag03; therefore, in the subsequent analyses, we mainly reported the effects of lag03. We observed a similar lag-patterns for EAD of all-cause, cardiovascular diseases, and respiratory diseases. In the single-day lag patterns, the effects of different size fractions on EAD decreased from lag0 to lag5 days, and negative associations were observed from lag3 to lag5 days in all-cause and cardiovascular diseases. In cumulative lag structures, $\mathrm{PM}_{2.5}, \mathrm{PM}_{2.5-10}$, and $\mathrm{PM}_{10}$ were significantly associated with EAD for all-cause, cardiovascular diseases and respiratory diseases. For example, the ER for a $10 \mu \mathrm{g} / \mathrm{m}^{3}$ increase in daily $\mathrm{PM}_{2.5}$, $\mathrm{PM}_{2.5-10}$ and $\mathrm{PM}_{10}$ at lag01 for cardiovascular diseases were $0.66 \%$ (95\% CI: $0.09,1.24 \%), 2.16 \%$ (0.99, 3.34\%), and $0.61 \%$ (95\% CI: $0.20,1.02 \%)$, respectively.

Table 2 illustrates the ER of EAD associated with per $10 \mu \mathrm{g} / \mathrm{m}^{3}$ increase in different size fractions in single and two-pollutant models at lag03. In single pollutant models, we observed statistically significant associations

Table 1 Description of air pollutants, meteorological factors and emergency ambulance dispatches between 2014 to 2018 in Guangzhou

\begin{tabular}{|c|c|c|c|c|c|c|c|}
\hline & \multirow{2}{*}{$\begin{array}{l}\text { No. of } \\
\text { missing days }\end{array}$} & \multirow{2}{*}{$\begin{array}{l}\text { Daily mean } \\
\text { (SD) }\end{array}$} & \multicolumn{5}{|c|}{ Quantiles } \\
\hline & & & Min & P25 & P50 & P75 & Max \\
\hline \multicolumn{8}{|l|}{ Pollutants, $\mu \mathrm{g} / \mathrm{m}^{3}$} \\
\hline $\mathrm{PM}_{2.5}$ & 17 & $36.0(19.0)$ & 4.6 & 22.0 & 31.7 & 46.8 & 148.3 \\
\hline $\mathrm{PM}_{2.5-10}$ & 17 & $20.5(9.2)$ & 1.3 & 14.5 & 18.7 & 25.0 & 62.2 \\
\hline $\mathrm{PM}_{10}$ & 17 & $56.5(26.1)$ & 10.0 & 37.5 & 50.4 & 71.1 & 208.3 \\
\hline $\mathrm{NO}_{2}$ & 17 & $44.1(17.4)$ & 11.7 & 31.7 & 40.4 & 52.1 & 155.0 \\
\hline $\mathrm{O}_{3}$ & 17 & $45.2(24.9)$ & 3.5 & 26.7 & 40.6 & 59.6 & 139.2 \\
\hline $\mathrm{SO}_{2}$ & 17 & $15.9(13.3)$ & 2.8 & 9.2 & 12.1 & 16.4 & 85.4 \\
\hline \multicolumn{8}{|l|}{ Meteorological factors } \\
\hline Temperature $\left({ }^{\circ} \mathrm{C}\right)$ & 0 & $22.2(6.1)$ & 3.4 & 17.5 & 23.8 & 27.4 & 32.8 \\
\hline Relative Humidity (\%) & 0 & $79.6(10.2)$ & 31.0 & 74.0 & 81.0 & 87.0 & 100.0 \\
\hline \multicolumn{8}{|c|}{ Emergency ambulance dispatches, $\mathrm{n}$} \\
\hline All-cause & 0 & $391(38.9)$ & 267 & 364 & 388 & 413 & 553 \\
\hline Cardiovascular diseases & 0 & $38(8.0)$ & 19 & 32 & 37 & 43 & 68 \\
\hline Respiratory diseases & 0 & $26(7.3)$ & 9 & 21 & 25 & 30 & 53 \\
\hline
\end{tabular}




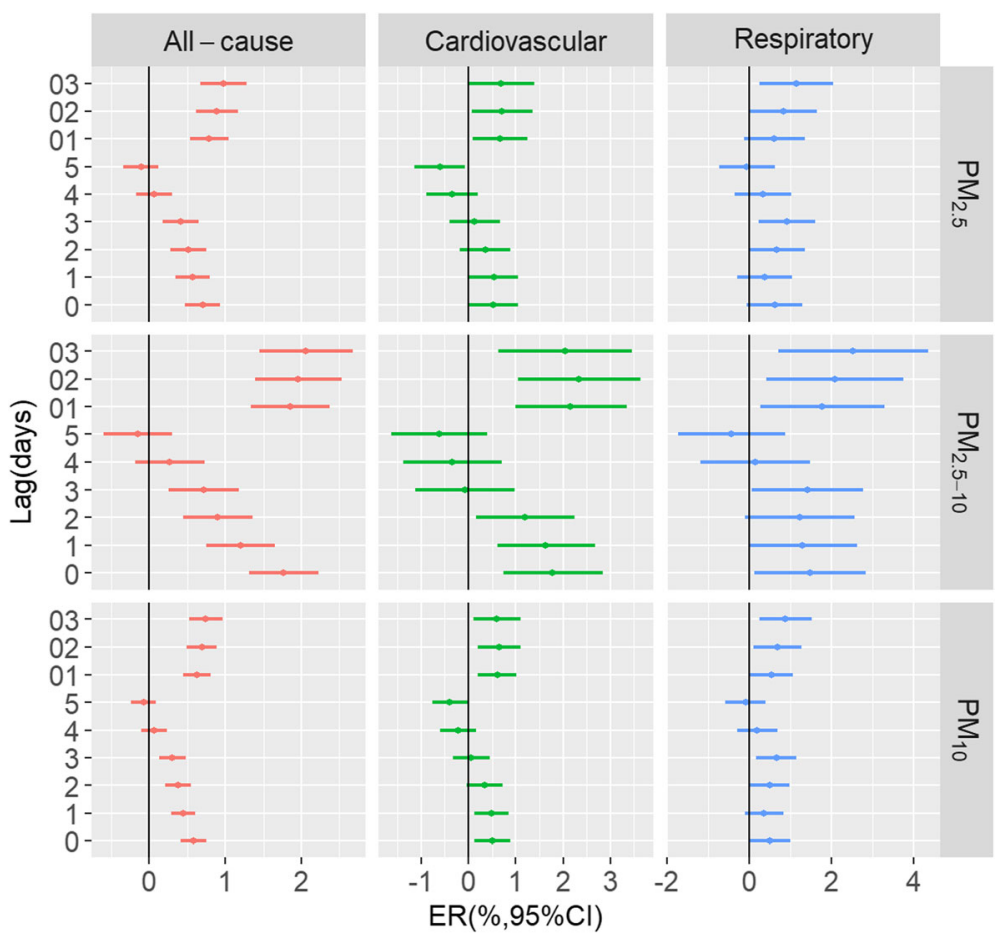

Fig. 2 Excess risk of emergency ambulance dispatches related to all-cause, cardiovascular diseases, and respiratory diseases for per $10 \mu \mathrm{gg} / \mathrm{m}^{3}$ increment in particulate pollutants with different lag days (single lags for the current day (lag0) to 5 days before the current day (lag5) and multiday lags for the current day and prior 1 day before (lag01), 2 days (lag02) or 3 days (lag03))

Table 2 Excess risk and 95\% confidence intervals of emergency ambulance dispatches for each $10 \mu \mathrm{g} / \mathrm{m}^{3}$ increment in PM pollution at lag03 in single and two-pollutant models in Guangzhou

\begin{tabular}{|c|c|c|c|c|}
\hline Pollutants & Models & All-cause & Cardiovascular & Respiratory \\
\hline \multicolumn{5}{|l|}{$\mathrm{PM}_{2.5}$} \\
\hline & Single pollutant model & $0.98(0.67,1.28)$ & $0.69(0.00,1.39)$ & $1.14(0.25,2.04)$ \\
\hline & Two-pollutant models & & & \\
\hline & Control for $\mathrm{NO}_{2}$ & $0.46(0.09,0.83)$ & $0.07(-0.78,0.92)$ & $1.21(0.12,2.31)$ \\
\hline & Control for $\mathrm{O}_{3}$ & $1.11(0.79,1.44)$ & $0.74(0.00,1.49)$ & $1.35(0.40,2.31)$ \\
\hline & Control for $\mathrm{SO}_{2}$ & $0.96(0.65,1.27)$ & $0.61(-0.10,1.33)$ & $1.03(0.12,1.94)$ \\
\hline \multicolumn{5}{|l|}{$\mathrm{PM}_{2.5-10}$} \\
\hline & Single pollutant model & $2.06(1.44,2.68)$ & $2.04(0.64,3.45)$ & $2.52(0.72,4.35)$ \\
\hline & Two-pollutant models & & & \\
\hline & Control for $\mathrm{NO}_{2}$ & $1.05(0.30,1.79)$ & $1.07(-0.64,2.81)$ & $2.82(0.60,5.10)$ \\
\hline & Control for $\mathrm{O}_{3}$ & $2.26(1.61,2.91)$ & $2.17(0.70,3.66)$ & $2.89(0.99,4.82)$ \\
\hline & Control for $\mathrm{SO}_{2}$ & $2.03(1.40,2.66)$ & $1.89(0.47,3.34)$ & $2.29(0.45,4.15)$ \\
\hline \multicolumn{5}{|l|}{$\mathrm{PM}_{10}$} \\
\hline & Single pollutant model & $0.75(0.53,0.96)$ & $0.60(0.11,1.10)$ & $0.89(0.25,1.52)$ \\
\hline & Two-pollutant models & & & \\
\hline & Control for $\mathrm{NO}_{2}$ & $0.38(0.12,0.65)$ & $0.18(-0.44,0.80)$ & $1.02(0.22,1.83)$ \\
\hline & Control for $\mathrm{O}_{3}$ & $0.85(0.62,1.08)$ & $0.65(0.13,1.18)$ & $1.05(0.38,1.73)$ \\
\hline & Control for $\mathrm{SO}_{2}$ & $0.74(0.52,0.96)$ & $0.55(0.04,1.05)$ & $0.80(0.16,1.45)$ \\
\hline
\end{tabular}


of different particle sizes with EAD for all-cause, cardiovascular diseases and respiratory diseases. In twopollutant models, the results remained robust after adjusting for $\mathrm{NO}_{2}, \mathrm{O}_{3}$, and $\mathrm{SO}_{2}$, albeit the effects were slightly reduced in some models. Meanwhile, the associations between different particle sizes and cardiovascular diseases weakened and became nonsignificant after controlling for $\mathrm{NO}_{2}$. Moreover, the effect of $\mathrm{PM}_{2.5}$ on cardiovascular diseases became non-significant when adjusted for $\mathrm{SO}_{2}$.

Table 3 shows the relationships between PM pollution and EAD stratified by gender, age and season. We found that the estimates varied by aforementioned factors, but the difference was only statistically significant for different age groups and seasons in the effects of $\mathrm{PM}_{2.5-10}$ on EAD. The estimates of PM with different sizes on allcause EAD were higher in males than females, while the effects reversed in cardiovascular diseases and respiratory diseases. In different age groups, EAD for all-cause, cardiovascular diseases, and respiratory diseases showed higher effects in the older group (age $\geq 65$ ). In season groups, $\mathrm{PM}_{2.5}$-EAD associations were stronger in the cold season; however, $\mathrm{PM}_{2.5-10^{-}}$EAD and $\mathrm{PM}_{10}$-EAD associations were stronger in the warm season.

Sensitivity analyses (Table S2) indicated that the results were insensitive when the $\mathrm{df}$ were changed. For example, regarding the effects of $\mathrm{PM}_{2.5}$, when the $\mathrm{df}$ of "temporal trends" was replaced from 6 to 8, the corresponding ERs were $0.89 \%$ (95\% CI: 0.58, 1.20\%) for all-cause EAD, $0.74 \%$ (95\% CI: 0.02, 1.46\%) for cardiovascular-related EAD, and $1.47 \%$ (95\% CI: 0.55, 2.39\%) for respiratory-related EAD at lag03. In another sensitivity analysis adjusting for temperature of longer lag days (up to 21 days), the effects remained largely consistent. Similar results were also observed when we controlled for relative humidity of longer lag days.

\section{Discussion}

Although previous evidence has linked PM pollution with adverse health outcomes worldwide [32, 33], only a few have investigated the PM effects on EAD. To our knowledge, our study is the first attempt to simultaneously examine the effects of particle size on the risk of EAD for all-cause, cardiovascular diseases, and respiratory diseases in China.

Ambient PM pollution is a critical public health concern in China. Our study observed that short-term exposures to $\mathrm{PM}_{2.5}, \mathrm{PM}_{2.5-10}$, and $\mathrm{PM}_{10}$ were significantly associated with risks of all EAD related to all-cause, cardiovascular, and respiratory diseases, which shared some similarities with previous studies [16, 34]. For example, one study in Japan reported that short-term exposure to $\mathrm{PM}_{2.5}$ was associated with EAD for all-cause (OR = 1.008, 95\% CI: 1.002, 1.014), and respiratory diseases
$(\mathrm{OR}=1.027,95 \%$ CI: 1.007, 1.048) at lag0 [34]. Besides, Xia's study found that $\mathrm{PM}_{2.5}$ and $\mathrm{PM}_{2.5-10}$ had effects on EAD due to cardiovascular diseases, with an OR of 1.07 (95\% CI: 1.04, 1.10) and 1.05 (95\% CI: 1.03, 1.07) at lag1, respectively [35]. Previous studies had reported several underlying mechanisms that could explain the increased EAD associated with PM pollution. For instance, PM had been found to be associated with increased systemic inflammatory responses, plasma viscosity [36], changes in blood pressure [37], decreased heart rate variability and increased cardiac arrhythmias [38].

Our study found that the effects of $\mathrm{PM}_{2.5-10}$ were higher than $\mathrm{PM}_{2.5}$ on all outcomes, which was consistent with results reported in previous studies. For instance, a timeseries study in Japan [39] found that each $10 \mu \mathrm{g} / \mathrm{m}^{3}$ increase in $\mathrm{PM}_{2.5-10}$ was associated with all-cause mortality (OR of 1.016, 95\%CI: 1.011, 1.022), which was higher than in $\mathrm{PM}_{2.5}$ (OR of 1.006, 95\%CI: 1.003, 1.009). Furthermore, while most research and regulatory agencies have directed their attention to $\mathrm{PM}_{2.5}$, our findings also emphasized the importance of monitoring and assessing $\mathrm{PM}_{2.5-10}$.

In our study, the effects of PM pollution on EAD seemed not to be confounded by $\mathrm{O}_{3}$ and $\mathrm{SO}_{2}$. However, the relationship between PM pollution and cardiovascular diseases became nonsignificant after adjusting for $\mathrm{NO}_{2}$. Because of moderate to high correlations between air pollutants (Table S1), it was difficult to ascertain their potential effects especially given the potential multicollinearity issue. In two pollutant models involving $\mathrm{PM}_{2.5}$ and $\mathrm{NO}_{2}$, this problem was even more apparent [40].

We estimated a larger effect of $\mathrm{PM}_{2.5}, \mathrm{PM}_{2.5-10}$ and $\mathrm{PM}_{10}$ on EAD due to all-cause, cardiovascular diseases, and respiratory diseases among older population than younger. Consistent results on the age-specific effects of particulate air pollution were reported previously [41, 42]. Part of the possible underlying explanations included that the older individuals usually had pre-existing illnesses and were in bad health status, and thus had diminished ability to respond to the acute exposure to high level of air pollution [43].

Our gender-stratified results illuminated that at the same concentration levels of air pollution, a higher risk of EAD for all-cause was observed among males compared with females, which was consistent with recent studies $[35,44]$. However, females had a slightly higher risk of cause-special EAD (such as cardiovascular diseases and respiratory diseases) than males, although the differences were not statistically significant. The discrepancy might be due to biological and behavioral differences between males and females, such as physiopathological responses to air pollution and time spent outdoors/indoor [45].

Furthermore, regarding the season-stratified analysis, the effects of $\mathrm{PM}_{2.5-10}$ on EAD were significantly stronger in the warm season. The potential reasons remained 
Table 3 Excess risks and 95\% confidence intervals of emergency ambulance dispatches associated with each $10 \mu \mathrm{g} / \mathrm{m}^{3}$ increase in $\mathrm{PM}_{2.5}, \mathrm{PM}_{2.5-10}$, and $\mathrm{PM}_{10}$ at lag03, stratified by gender, age and season ${ }^{*}$

\begin{tabular}{|c|c|c|c|c|}
\hline Pollutants & Stratum & All-cause & Cardiovascular & Respiratory \\
\hline \multicolumn{5}{|l|}{$\mathrm{PM}_{2.5}$} \\
\hline & \multicolumn{4}{|l|}{ Gender } \\
\hline & Male & $1.01(0.56,1.46)$ & $0.38(-0.78,1.55)$ & $0.80(-0.67,2.29)$ \\
\hline & Female & $0.54(0.08,0.99)$ & $0.48(-0.49,1.45)$ & $1.03(-0.14,2.22)$ \\
\hline & \multicolumn{4}{|l|}{ Age } \\
\hline & $<65$ & $0.63(0.14,1.13)$ & $0.37(-0.71,1.47)$ & $-0.67(-2.18,0.86)$ \\
\hline & $\geq 65$ & $1.06(0.61,1.51)$ & $0.99(0.02,1.97)$ & $1.81(0.73,2.89)$ \\
\hline & \multicolumn{4}{|l|}{ Season } \\
\hline & Warm & $0.84(0.31,1.37)$ & $0.74(-0.62,2.12)$ & $1.93(0.25,3.64)$ \\
\hline & Cold & $1.02(0.65,1.39)$ & $1.06(0.17,1.95)$ & $2.05(0.93,3.17)$ \\
\hline \multicolumn{5}{|l|}{$\mathrm{PM}_{2.5-10}$} \\
\hline & \multicolumn{4}{|l|}{ Sex } \\
\hline & Male & $1.79(0.88,2.71)$ & $1.24(-0.68,3.20)$ & $1.93(-0.43,4.34)$ \\
\hline & Female & $1.45(0.54,2.38)$ & $2.15(-0.18,4.53)$ & $2.72(-0.24,5.76)$ \\
\hline & \multicolumn{4}{|l|}{ Age } \\
\hline & $<65$ & $0.54(-0.45,1.54)$ & $2.03(0.10,4.01)$ & $-0.42(-3.42,2.66)$ \\
\hline & $\geq 65$ & $2.62(1.72,3.54)$ & $2.32(0.14,4.55)$ & $3.52(1.34,5.74)$ \\
\hline & \multicolumn{4}{|l|}{ Season } \\
\hline & Warm & $2.77(1.41,4.15)$ & $5.60(2.08,9.23)$ & $4.36(2.15,6.61)$ \\
\hline & Cold & $1.84(1.11,2.59)$ & $1.58(-0.15,3.33)$ & $3.82(-0.51,8.34)$ \\
\hline \multicolumn{5}{|l|}{$\mathrm{PM}_{10}$} \\
\hline & \multicolumn{4}{|l|}{ Sex } \\
\hline & Male & $0.73(0.41,1.05)$ & $0.40(-0.29,1.08)$ & $0.74(-0.30,1.79)$ \\
\hline & Female & $0.45(0.13,0.77)$ & $0.46(-0.36,1.28)$ & $0.76(-0.07,1.59)$ \\
\hline & \multicolumn{4}{|l|}{ Age } \\
\hline & $<65$ & $0.38(0.03,0.74)$ & $0.48(-0.29,1.25)$ & $-0.39(-1.46,0.69)$ \\
\hline & $\geq 65$ & $0.86(0.54,1.18)$ & $0.75(0.06,1.44)$ & $1.34(0.58,2.10)$ \\
\hline & \multicolumn{4}{|l|}{ Season $^{a}$} \\
\hline & Warm & $0.76(0.35,1.17)$ & $0.95(-0.10,2.01)$ & $1.53(0.76,2.31)$ \\
\hline & Cold & $0.72(0.46,0.98)$ & $0.71(0.10,1.32)$ & $1.50(0.20,2.82)$ \\
\hline
\end{tabular}

"Data in bold indicated that the differences between the effect estimates of the strata were statistically significant $(p<0.05)$

${ }^{a}$ Warm season was defined as April to September, and cold season was October to March

largely unclear. However, several factors may account for aggravated effects in the warm seasons. For example, high temperatures could increase blood viscosity and cholesterol, contributing to thrombosis [46]; people preferred to stay outdoors in warm seasons than in cold seasons, which increased the risk of exposure to PM [47]; and thermoregulation system responded heat stress by increasing sweating, minute ventilation, and cardiac output, all of which tend to increase the uptake and distribution of air pollutants in the human body $[15,48]$, to mention a few.

Several limitations of this study should be noted. We used air pollution concentration measured at fixed air monitoring stations to represent personal exposure, making exposure misclassification possible; however, using daily air pollutant concentrations (averaged over all available stations) as measures of exposure was considered acceptable in ecological studies [49]. Furthermore, as an ecological study, this study was limited in controlling unmeasured potential confounders because of the limited data. For instance, some important variables including living environment, history of diseases, and lifestyle patterns were not available in this study. It was unknown about whether these variables would represent a threat to validity of our results because no analyses could be performed. Moreover, our study was 
performed in just one Chinese city due to data accessibility, which may impair the generalizability of our results. Even though it had been reported that EAD could serve as a morbidity indicator and even be more appropriate to capture the short-term effects of air pollutants than mortality, the associations between EAD and morbidity and mortality required more justifications. Unfortunately no analyses could be conducted in our study due to lack of the information on mortality and morbidity. Further evidence would be largely needed to assess the relationship between the use of EAD and morbidity and mortality outcomes.

\section{Conclusion}

In conclusion, $\mathrm{PM}_{2.5}, \mathrm{PM}_{2.5-10}$ and $\mathrm{PM}_{10}$ were found to be significantly related with EAD, while gender, age, and season might be important effect modifiers in these relationships. More evidence of high quality may be needed to further support our results in this ecological study.

\section{Supplementary information}

Supplementary information accompanies this paper at https://doi.org/10. 1186/s12940-020-00619-5.

Additional file 1: Table S1. Pearson correlation coefficients between the daily mean concentrations of air pollutants between 2014 to 2018 in Guangzhou. Table S2. Sensitivity analysis for emergency ambulance dispatches associated with each $10 \mu \mathrm{g} / \mathrm{m}^{3}$ increment of different size fractions of particulate matter pollution at lag03.

\section{Abbreviations}

EAD: Emergency ambulance dispatches; Cl: Confidential intervals; RR: Relative risk; ER: Excess risk; WHO: World Health Organization; PM: Particulate matter; $\mathrm{PM}_{10}$ : Particulate matter with an aerodynamic diameter $\leq 10 \mathrm{~mm} ; \mathrm{PM}_{2.5}$ 10: Particulate matter between 2.5 and $10 \mu \mathrm{m}$ in aerodynamic diameter; $\mathrm{PM}_{2.5}$ : Particulate matter with an aerodynamic diameter $\leq 2.5 \mathrm{~mm} \mathrm{SO}_{2}$ : Sulfur dioxide; $\mathrm{NO}_{2}$ : Nitrogen dioxide; $\mathrm{O}_{3}$ : Ozone; GAM: Generalized additive models; DOW: Day of the week; PH: Public holidays; df: Degrees of freedom

\section{Acknowledgments}

We are grateful to the reviewers for their valuable comments and suggestions.

\section{Authors' contributions}

Study concept and design were contributed by XW; statistical analysis was contributed by XW; drafting of manuscript was contributed by XW, JT, ZL, and GL; All authors contributed to interpretation of results and manuscript editing; All authors read and approved the final manuscript.

\section{Funding}

This study was supported by the Guangzhou medical and health science and technology project (20161A031004) and the Science Foundation of Guangdong Second Provincial General Hospital (YY2018-002).

\section{Availability of data and materials}

Please contact author for data requests.

Ethics approval and consent to participate

Not applicable.

\section{Consent for publication}

Not applicable.

\section{Competing interests}

The authors declare that they have no competing interests.

\section{Author details}

${ }^{1}$ Center for Clinical Epidemiology and Methodology (CCEM), Guangdong Second Provincial General Hospital, Guangzhou, China. ${ }^{2}$ Department of Cardiology, Guangdong Second Provincial General Hospital, Guangzhou, China. ${ }^{3}$ Department of Health research methods, Evidence, and Impact (HEI), McMaster University, 1280 Main St West, Hamilton, ON L8S 4L8, Canada.

Received: 11 February 2020 Accepted: 29 May 2020

Published online: 17 June 2020

\section{References}

1. Chen R, Yin P, Meng X, Liu C, Wang L, Xu X, Ross JA, Tse LA, Zhao Z, Kan H, et al. Fine particulate air pollution and daily mortality. A Nationwide analysis in 272 Chinese cities. Am J Respir Crit Care Med. 2017;196(1):73-81.

2. Kim K-H, Kabir E, Kabir S. A review on the human health impact of airborne particulate matter. Environ Int. 2015;74:136-43.

3. Qi J, Ruan Z, Qian ZM, Yin P, Yang Y, Acharya BK, Wang L, Lin H. Potential gains in life expectancy by attaining daily ambient fine particulate matter pollution standards in mainland China: a modeling study based on nationwide data. PLoS Med. 2020;17(1):e1003027.

4. WHO: Ambient (outdoor) air pollution. https://www.who.int/en/news-room/ fact-sheets/detail/ambient-(outdoor)-air-quality-and-health. 2018. Accessed 2 May 2018.

5. Li G, Xue M, Zeng Q, Cai Y, Pan X, Meng Q. Association between fine ambient particulate matter and daily total mortality: an analysis from 160 communities of China. Sci Total Environ. 2017;599-600:108-13.

6. Mukherjee A, Agrawal M. A global perspective of fine particulate matter pollution and its health effects. Rev Environ Contam Toxicol. 2018;244:5-51.

7. Di Q, Dai L, Wang Y, Zanobetti A, Choirat C, Schwartz JD, Dominici F. Association of short-term exposure to air pollution with mortality in older adults. JAMA. 2017;318(24):2446-56

8. Keet CA, Keller JP, Peng RD. Long-term coarse particulate matter exposure is associated with asthma among children in Medicaid. Am J Respir Crit Care Med. 2018:197(6):737-46.

9. Zhao Y, Wang S, Lang L, Huang C, Ma W, Lin H. Ambient fine and coarse particulate matter pollution and respiratory morbidity in Dongguan, China. Environ Pollut. 2017;222:126-31.

10. Dominici F, Peng RD, Bell ML, Pham L, McDermott A, Zeger SL, Samet JM. Fine particulate air pollution and hospital admission for cardiovascular and respiratory diseases. JAMA. 2006;295(10):1127-34

11. Achilleos S, Kioumourtzoglou M-A, Wu C-D, Schwartz JD, Koutrakis P, Papatheodorou SI. Acute effects of fine particulate matter constituents on mortality: a systematic review and meta-regression analysis. Environ Int. 2017;109:89-100.

12. Phung VLH, Ueda K, Kasaoka S, Seposo X, Tasmin S, Yonemochi S, Phosri A, Honda A, Takano H, Michikawa T, et al. Acute Effects of Ambient PM(2.5) on All-Cause and Cause-Specific Emergency Ambulance Dispatches in Japan. Int J Environ Res Public Health. 2018;15(2):307.

13. Salimi F, Henderson SB, Morgan GG, Jalaludin B, Johnston FH. Ambient particulate matter, landscape fire smoke, and emergency ambulance dispatches in Sydney, Australia. Environ Int. 2017;99:208-12.

14. Youngquist ST, Hood CH, Hales NM, Barton CC, Madsen TE, Arden Pope C Association between EMS calls and fine particulate air pollution in Utah. Air Qual Atmosphere Health. 2016;9(8):887-97.

15. Ai S, Wang C, Qian ZM, Cui Y, Liu Y, Acharya BK, Sun X, Hinyard L, Jansson DR, Qin L, et al. Hourly associations between ambient air pollution and emergency ambulance calls in one central Chinese city: implications for hourly air quality standards. Sci Total Environ. 2019;696:133956.

16. Liu R, Zeng J, Jiang X, Chen J, Gao X, Zhang L, Li T. The relationship between airborne fine particle matter and emergency ambulance dispatches in a southwestern city in Chengdu, China. Environ Pollut. 2017; 229:661-7.

17. Ichiki T, Onozuka D, Kamouchi M, Hagihara A. An association between fine particulate matter (PM2.5) levels and emergency ambulance dispatches for cardiovascular diseases in Japan. Int Arch Occup Environ Health. 2016;89(8): 1329-35.

18. Lin H, Tao J, Du Y, Liu T, Qian Z, Tian L, Di Q, Rutherford S, Guo L, Zeng W, et al. Particle size and chemical constituents of ambient particulate 
pollution associated with cardiovascular mortality in Guangzhou, China. Environ Pollut. 2016;208(Pt B):758-66.

19. Lin H, Tao J, Du Y, Liu T, Qian Z, Tian L, Di Q, Zeng W, Xiao J, Guo L, et al. Differentiating the effects of characteristics of PM pollution on mortality from ischemic and hemorrhagic strokes. Int J Hyg Environ Health. 2016; 219(2):204-11.

20. Yu ITS, Hui Zhang Y, San Tam WW, Yan QH, Jun Xu Y, Jun Xun X, Wu W, Ma WJ, Tian LW, Tse LA. Effect of ambient air pollution on daily mortality rates in Guangzhou, China. Atmos Environ. 2012;46:528-35.

21. Tao J, Shen Z, Zhu C, Yue J, Cao J, Liu S, Zhu L, Zhang R. Seasonal variations and chemical characteristics of sub-micrometer particles (PM1) in Guangzhou, China. Atmos Res. 2012;118:222-31.

22. Yang C, Chen A, Chen R, Qi Y, Ye J, Li S, Li W, Liang Z, Liang Q, Guo D, et al. Acute effect of ambient air pollution on heart failure in Guangzhou, China. Int J Cardiol. 2014;177(2):436-41.

23. Wang X, Zhang L, Yao Z, Ai S, Qian ZM, Wang H, BeLue R, Liu T, Xiao J, Li X, et al. Ambient coarse particulate pollution and mortality in three Chinese cities: association and attributable mortality burden. Sci Total Environ. 2018; 628-629:1037-42.

24. Zhang L, Yang Y, Li Y, Qian ZM, Xiao W, Wang X, Rolling CA, Liu E, Xiao J, Zeng $W$, et al. Short-term and long-term effects of PM2.5 on acute nasopharyngitis in 10 communities of Guangdong, China. Sci Total Environ. 2019;688:136-42.

25. Ruan Z, Qian ZM, Xu Y, Wu J, Kan H, Yang Y, Acharya BK, Jiang C, Syberg KM, Iwelunmor J, et al. Applying the concept of "number needed to treat" to the formulation of daily ambient air quality standards. Chemosphere. 2019;222:665-70.

26. Peng RD, Dominici F, Louis TA. Model choice in time series studies of air pollution and mortality. J Roy Statist Soc Ser A. 2006;169(2):179-203.

27. Curriero FC, Heiner KS, Samet JM, Zeger SL, Strug L, Patz JA. Temperature and mortality in 11 cities of the eastern United States. Am J Epidemiol. 2002:155(1):80-7.

28. Tian L, Qiu H, Pun VC, Lin H, Ge E, Chan JC, Louie PK, Ho K-F, Yu ITS Ambient carbon monoxide associated with reduced risk of hospital admissions for respiratory tract infections. Am J Respir Crit Care Med. 2013; 188(10):1240-5.

29. Son J-Y, Lee J-T, Kim K-H, Jung K, Bell ML. Characterization of fine particulate matter and associations between particulate chemical constituents and mortality in Seoul, Korea. Environ Health Perspect. 2012;120(6):872-8.

30. Zeka A, Zanobetti A, Schwartz J. Individual-level modifiers of the effects of particulate matter on daily mortality. Am J Epidemiol. 2006;163(9):849-59.

31. Ma W, Wang L, Lin H, Liu T, Zhang Y, Rutherford S, Luo Y, Zeng W, Zhang Y, Wang $X$, et al. The temperature-mortality relationship in China: an analysis from 66 Chinese communities. Environ Res. 2015;137:72-7.

32. Braithwaite I, Zhang S, Kirkbride JB, Osborn DPJ, Hayes JF. Air pollution (particulate matter) exposure and associations with depression, anxiety, bipolar, psychosis and suicide risk: a systematic review and meta-analysis. Environ Health Perspect. 2019;127(12):126002.

33. Vanasse A, Talbot D, Chebana F, Bélanger D, Blais C, Gamache P, Giroux J-X, Dault $R$, Gosselin P. Effects of climate and fine particulate matter on hospitalizations and deaths for heart failure in elderly: a population-based cohort study. Environ Int. 2017;106:257-66.

34. Michikawa T, Ueda K, Takeuchi A, Kinoshita M, Hayashi H, Ichinose T, Nitta H. Impact of short-term exposure to fine particulate matter on emergency ambulance dispatches in Japan. J Epidemiol Community Health. 2015;69(1): 86-91.

35. Xia R, Zhou G, Zhu T, Li X, Wang G. Ambient air pollution and out-ofhospital cardiac arrest in Beijing, China. Int J Environ Res Public Health. 2017;14(4):423.

36. Hoffmann B, Moebus S, Dragano N, Stang A, Möhlenkamp S, Schmermund A, Memmesheimer M, Bröcker-Preuss M, Mann K, Erbel R, et al. Chronic residential exposure to particulate matter air pollution and systemic inflammatory markers. Environ Health Perspect. 2009;117(8):1302-8.

37. Auchincloss AH, Diez Roux AV, Dvonch JT, Brown PL, Barr RG, Daviglus ML, Goff DC, Kaufman JD, O'Neill MS. Associations between recent exposure to ambient fine particulate matter and blood pressure in the multi-ethnic study of atherosclerosis (MESA). Environ Health Perspect. 2008;116(4):48691.

38. Du Y, Xu X, Chu M, Guo Y, Wang J. Air particulate matter and cardiovascular disease: the epidemiological, biomedical and clinical evidence. J Thoracic Ddis. 2016;8(1):E8.
39. Yorifuji T, Kashima S, Doi H. Associations of acute exposure to fine and coarse particulate matter and mortality among older people in Tokyo, Japan. Sci Total Environ. 2016;542(Pt A):354-9.

40. Stafoggia M, Samoli E, Alessandrini E, Cadum E, Ostro B, Berti G, Faustini A Jacquemin B, Linares C, Pascal M, et al. Short-term associations between fine and coarse particulate matter and hospitalizations in southern Europe: results from the MED-PARTICLES project. Environ Health Perspect. 2013; 121(9):1026-33.

41. Qiu H, Tian L, Ho K-F, Pun VC, Wang X, Yu ITS. Air pollution and mortality: effect modification by personal characteristics and specific cause of death in a case-only study. Environ Pollut. 2015;199:192-7.

42. Cakmak S, Dales RE, Rubio MA, Vidal CB. The risk of dying on days of higher air pollution among the socially disadvantaged elderly. Environ Res. 2011; 111(3):388-93.

43. Lin H, Liu T, Xiao J, Zeng W, Li X, Guo L, Zhang Y, Xu Y, Tao J, Xian H, et al. Mortality burden of ambient fine particulate air pollution in six Chinese cities: results from the Pearl River Delta study. Environ Int. 2016;96:91-7.

44. Xie J, He M, Zhu W. Acute effects of outdoor air pollution on emergency department visits due to five clinical subtypes of coronary heart diseases in shanghai, China. J Epidemiol. 2014;24(6):452-9.

45. Ma Y, Zhao Y, Yang S, Zhou J, Xin J, Wang S, Yang D. Short-term effects of ambient air pollution on emergency room admissions due to cardiovascular causes in Beijing, China. Environ Pollut. 2017;230:974-80.

46. Carder M, McNamee R, Beverland I, Elton R, Van Tongeren M, Cohen GR, Boyd J, Macnee W, Agius RM. Interacting effects of particulate pollution and cold temperature on cardiorespiratory mortality in Scotland. Occup Environ Med. 2008;65(3):197-204

47. Li J, Woodward A, Hou X-Y, Zhu T, Zhang J, Brown H, Yang J, Qin R, Gao J, Gu S, et al. Modification of the effects of air pollutants on mortality by temperature: a systematic review and meta-analysis. Sci Total Environ. 2017; 575:1556-70.

48. Gordon CJ. Role of environmental stress in the physiological response to chemical toxicants. Environ Res. 2003:92(1):1-7.

49. Kim D, Sass-Kortsak A, Purdham JT, Dales RE, Brook JR. Associations between personal exposures and fixed-site ambient measurements of fine particulate matter, nitrogen dioxide, and carbon monoxide in Toronto, Canada. J Expo Sci Environ Epidemiol. 2006;16(2):172-83.

\section{Publisher's Note}

Springer Nature remains neutral with regard to jurisdictional claims in published maps and institutional affiliations.

Ready to submit your research? Choose BMC and benefit from:

- fast, convenient online submission

- thorough peer review by experienced researchers in your field

- rapid publication on acceptance

- support for research data, including large and complex data types

- gold Open Access which fosters wider collaboration and increased citations

- maximum visibility for your research: over $100 \mathrm{M}$ website views per year

At $\mathrm{BMC}$, research is always in progress.

Learn more biomedcentral.com/submissions 